\title{
Novel Citric Acid Dendritic Hydrogels for the Delivery of Econazole Nitrate and its Antifungal Activity
}

\author{
B. Narasimha Rao ${ }^{1}$, S. Rahath Fathima ${ }^{1}$, V. Viswanath ${ }^{1}, \mathrm{~K}_{\text {Gnana Prakash }}{ }^{1}$, D. Sai Padmini ${ }^{2}$, P. Salomi Reddy ${ }^{3}$ \\ ${ }^{1}$ Dept. of Pharmaceutics, PRRM College of Pharmacy, Prakruthi Nagar, Utukur, Kadapa, A.P., India. \\ ${ }^{2}$ Dept. of Pharmaceutical Chemistry, PRRM College of Pharmacy, Utukur, Kadapa, A.P., India. \\ ${ }^{3}$ Dept. of Pharmaceutical Analysis, PRRM College of Pharmacy, Utukur, Kadapa, A.P., India.
}

\begin{tabular}{l} 
ARTICLE INFO \\
\hline Article history: \\
Received on: 01/09/2016 \\
Revised on: $17 / 10 / 2016$ \\
Accepted on: 04/11/2016 \\
Available online: $28 / 12 / 2016$ \\
\hline Key words: \\
Citric acid dendrimer, \\
Econazole, Hydrogels, \\
Antifungal activity, \\
lipophilicity.
\end{tabular}

\begin{abstract}
Econazole is an imidazole derivative antifungal drug with distinguished antifungal properties. But the bioavailability of conventional econazole preparations is poor because of poor solubility and lipophilicity or lipophilic nature. Thus frequent application of the preparation is required to maintain therapeutic levels at the site of action. Such repeated doses may produce toxic affects thereby limiting the clinical use of the drug. Citric acid dendrimers give an opportunity to overcome the above limitations by improving its solubilization and drug permeation properties. Thus, the aim of current study is to design citric acid dendrimer hydrogels and study its influence on the drug release and anti-fungal activity of loaded drug. Dendritic architecture and size strongly influences the invitro release and antifungal activity of drug. Antifungal activity of designed Econazole hydrogel was measured by Agar plate diffusion method. Zone of inhibition values showed that citric acid dendrimers considerably enhanced the antifungal activity of Econazole to a greater extent and the effect was more with lower generation hydrogels. The operative mechanism is probably the smaller size $(\mathrm{G} 2)$ that penetrates the fungal cell membrane more efficiently than higher generation (G3 and G4) hydrogels.
\end{abstract}

\section{INTRODUCTION}

Econazole is an imidazole antifungal derivative, used primarily for the treatment of both systemic and topical fungal infections (Albertini et al., 2009). It is believed that econazole interacts with a cytochrome P-450 enzyme, 14- $\alpha$ demethylase that converts lanosterol to ergosterol. Ergosterol is an important constituent of fungal cell membrane. As econazole inhibits its formation, then there might be increased cellular permeability followed by leakage of cellular contents (Vera-Cabrera et al., 2010). In addition, econazole also inhibits endogenous respiration, transformation of yeasts to their respective mycelial forms, interaction with membrane phospholipids, purine uptake and biosynthesis of phospholipids and triglycerides. In spite of these, econazole is lipophilic in nature and practically insoluble in water (Pandey et al., 2005). This property limits the use of econazole in designing pharmaceutical formulations as therapeutic efficiency of the formulation will also get decreased. Since then various efforts have been made for the development

\footnotetext{
* Corresponding Author

E-mail:simham1985@gmail.com
}

of efficient carrier systems that overcome the limitations of Econazole and improve the therapeutic efficiency of the drug.

Citric acid dendrimers is an approach towards improving therapeutic efficiency, solubility and bioavailability of entrapped drugs. Dendrimers are a class of monodispersed polymers with definite molecular weight and host-guest entrapment properties (Tomalia, 2004). Because of their repeated branching nature and nanometer size; dendrimers are considered most suitable for targeting therapeutic agents to the target site (Svenson, 2009). Among all dendrimers, citric acid dendrimers are popular and easy to synthesize. They have been considered as vehicles for different routes of delivery such as oral, Transdermal, ocular, i.v etc (Cheng et al., 2008). Considering the use of dendrimers for drug delivery, it should be noted that they are bio-compatible, non-toxic (Jain et al., 2010). They offer various advantages over linear polymers when used in drug delivery design (Amaresh, 2012). Their monodispersed nature and nanometer size range allows easy passage of dendrimers across biological barriers (Kakade et al., 2013). Therapeutic agents get attached either to the surface or interior of the citric acid dendrimers through covalent conjugation or electrostatic interaction (Tambe et al.,). 
Moreover, it is said that some dendrimers itself possess a little anti-bacterial and anti-fungal activity (Janiszewska et al., 2012). Thus, in the treatment of fungal and bacterial infections, dendrimers play an additive role besides being carriers for the drug (Winnicka et al., 2011). Treatment of any skin infections requires maximum concentration of drug at the target site and clinical efficacy depends on the ability of drug to penetrate skin barriers and prevent fungal growth (Alberti et al., 2001). As our skin is negatively charged, cationic dendrimers are supposed to interact with the skin and increase its permeability ${ }^{13}$. Further, dendrimers being carriers, serve the lipophilic drug in a solubilized form to the skin from where it get transported to stratum corneum more efficiently owing to the high affinity of hydrophobic forms to skin lipids (Venuganti and Perumal, 2009,2008).

In current study, an attempt was made to design and deliver citric acid dendrimers encapsulating an antifungal agent in a semisolid i.e. hydrogel form. Further, the influence of citric acid dendrimers on the invitro drug release and anti-fungal activity of drug on pathogenic fungal strains were also studied.

\section{MATERIALS AND METHODS}

\section{Materials}

Econazole nitrate (Yarrow Chemicals, Mumbai), Polyethylene glycol 400 (Finar chemicals Pvt. Ltd., Ahmedabad), Sodium Carbonate, Potassium Permanganate, Thionyl Chloride,Dimethyl formamide, Propylene glycol, Tween 80 ( $\mathrm{Sd}$ Fine Chemicals Ltd., Mumbai), Pyridine, Diethyl ether and Carbopol 934 were used for the synthesis of Econazole dendrimer hydrogels. All the procured chemicals were of analytical grade.

\section{Method of Preparation}

Preparation of Econazole dendrimer gel is a lengthy process and involves the following steps:

a. Synthesis of citric acid dendrimers

b. Drug loading in the synthesized dendrimers

c. Preparation of hydrogels of constructed Econazole dendrimers

\section{Synthesis of 4 generations of citric acid dendrimers:}

Citric acid dendrimers can be synthesized following Divergent technique based on the established and reported procedure:

Step 1: for the synthesis of dendrimers, 35.5gms of Potassium permanganate was weighed and dissolved completely in $694 \mathrm{ml}$ of water in a beaker. In another beaker, 3.75gms of Sodium carbonate was dissolved in $38 \mathrm{ml}$ of water. Both the solutions were mixed together with the addition of $110 \mathrm{ml}$ of Polyethylene glycol and stirred with the help of a magnetic stirrer for about 3-4hrs followed by cooling the mixture at $4-5^{\circ} \mathrm{C}$ by immersing in an ice bath for 20 minutes. Obtained reaction mixture was filtered and collected filtrate was heated and cooled continuously till a $100 \mathrm{ml}$ concentrated liquid was obtained. This solution was covered with a layer of ether and after sometime both aqueous and ether layers were separated using a separating funnel. The collected aqueous layer was heated in a mantle at $70^{\circ} \mathrm{C}$ for the complete removal of ether from the mixture leaving behind a white precipitate. The so obtained precipitate is Polyethylene glycol diacid, nothing but Generation 1 dendrimer.

Step 2: G1 dendrimer was treated with $6 \mathrm{ml}$ of Thionyl chloride in a round-bottomed flask equipped with condenser and magnetic stirrer for 45-60min. Mixture obtained after condensation was heated to $70^{\circ} \mathrm{C}$ to collect Chlorinated Polyethylene glycol, which is a G1.5 dendrimer. Obtained G1.5 was dissolved in $20 \mathrm{ml}$ of DMF and kept in ice bath for 24hrs. Simultaneously, in another beaker100mg of citric acid as dissolved in $10 \mathrm{ml}$ of DMF and $120 \mathrm{ml}$ of pyridine and placed on an ice bath overnight. Next day, both the solutions were taken from ice bath, mixed and incubated at $50-60^{\circ} \mathrm{C}$ in an incubator for 6hrs. Product obtained was Generation 2 dendrimer, which was further purified by Column Chromatography. In order to obtain G4 dendrimer, steps of step 2 was repeated continuously with increasing amounts of Thionyl chloride and citric acid (Reddy et al., 2014) (Table 1).

\section{Drug loading in the synthesized dendrimers}

For the purpose of drug loading, synthesized dendrimer was made to dissolve in $10 \mathrm{ml}$ of DMF and $10 \mathrm{mg}$ of Econazole, dissolved in a suitable solvent (i.e methanol) was added drop wise to the dendrimer solution. Drug-dendrimer solution was stirred on a magnetic stirrer for $24 \mathrm{hrs}$ at $50 \mathrm{rpm}$ speed. Amount of drug encapsulated in the dendrimers was estimated spectrophotometrically through UV spectrophotometer at $271.5 \mathrm{~nm}$ (Rao et al., 2015).

\section{Preparation of Dendrimer hydrogels}

Econazole loaded dendrimer gels were prepared by Dispersion method. As per the method, gelling agent ie., carbopol 934 was soaked in water $2 \mathrm{hrs}$ before prior to preparation. Later, it was stirred to a homogenous mixture at a temperature of $40^{\circ} \mathrm{C}$. The above mixture was neutralized with the drop wise addition of $20 \% \mathrm{NaOH}$ solution to allow gel formation. In another beaker, methyl paraben and propyl paraben were dissolved in ethanol and added to carbopol mixture and stirred well. Tween 80 and propylene glycol were added to the hydrogel base with continuous stirring.

Finally drug loaded dendrimer solution was added to the above hydrogel to give out Econazole dendrimer hydrogel (Sosnowska and Winnicka, 2013) (Table no.2). 
Table 1: Formulation of Dendrimers.

\begin{tabular}{cccccccc}
\hline Formulation & KMNO $_{\mathbf{4}}$ & $\mathbf{N a}_{\mathbf{2}} \mathbf{C O}_{\mathbf{3}}$ & PEG400 & Thionyl chloride & Citric acid & Pyridine & DMF \\
\hline F1(G1) & $35.5 \mathrm{gm}$ & $3.75 \mathrm{gm}$ & $110 \mathrm{ml}$ & - & - & - & - \\
F2(G2) & $35.5 \mathrm{gm}$ & $3.75 \mathrm{gm}$ & $110 \mathrm{ml}$ & $6 \mathrm{ml}$ & $0.1 \mathrm{~g}$ & $100 \mathrm{ml}$ & $30 \mathrm{ml}$ \\
F3(G3) & $35.5 \mathrm{gm}$ & $3.75 \mathrm{gm}$ & $110 \mathrm{ml}$ & $8 \mathrm{ml}$ & $0.2 \mathrm{gm}$ & $100 \mathrm{ml}$ & $30 \mathrm{ml}$ \\
F4(G4) & $35.5 \mathrm{gm}$ & $3.75 \mathrm{gm}$ & $110 \mathrm{ml}$ & $10 \mathrm{ml}$ & $0.4 \mathrm{gm}$ & $100 \mathrm{ml}$ & $30 \mathrm{ml}$ \\
\hline
\end{tabular}

Table 2: Formulation of Dendrimer Hydrogels.

\begin{tabular}{lll}
\hline S. No. & Ingredients & Quantity \\
\hline 1. & Econazole loaded dendrimer solution & $2 \mathrm{ml}$ \\
2. & Carbopol 934 & $34 \mathrm{mg}$ \\
3. & Propylene Glycol & $2 \mathrm{ml}$ \\
4. & Sodium Hydroxide & q.s \\
5. & Tween 80 & $0.2 \mathrm{ml}$ \\
6. & Methyl Paraben & q.s \\
7. & Propyl Paraben & q.s \\
8. & Ethanol & $2 \mathrm{ml}$ \\
9. & Water & $10 \mathrm{ml}$ \\
\hline
\end{tabular}

\section{Characterization of dendrimers}

Econazole loaded dendrimers were characterized by IR spectroscopy and Differential Scanning calorimetry

\section{FT-IR studies}

FT-IR spectra of drug, plain dendrimers and drug loaded dendrimers were performed to confirm the drug loading and compatibility between drug and dendrimers. It was carried using FT-IR spectrophotometer (Bruker, Germany) in the region $4000 \mathrm{~cm}^{-1}$ to $400 \mathrm{~cm}^{-1}$. Samples were mixed with Potassium bromide in the ratio 100:1 and compressed to discs by applying pressure of $10 \mathrm{~kg}$ in a hydraulic press. Obtained pellet was placed under light path and spectra were recorded (Reddy et al., 2014).

\section{Differential scanning calorimetry}

DSC of drug and drug loaded dendrimer samples was performed to examine the thermal stability of drug and drug loaded samples over a range of temperatures. DSC studies were performed using DSC module (DSC Q20 V24.11 Build 124, USA). Known quantity of drug and drug loaded samples was placed in an aluminium pan and lid was tucked onto pan. Pan was then kept on a sample holder whose temperature was equilibrated at $35^{\circ} \mathrm{C}$. Later, temperature was raised at a rate of $10^{\circ} \mathrm{C} / \mathrm{min}$ under nitrogen gas pressure till the sample gets deteriorated. In the resulting curve, temperatures for each curve were obtained. The curves provided information regarding stability and phase transitions for studied samples (Vijayakumar et al., 2012).

\section{Zeta potential}

Zeta potential is an indicator of stability of the synthesized dendrimers and measured using Zeta Sizer. It is the measure of extent of electrostatic attractive or repulsive forces between the particles (Zaman et al., 2014). Smaller particles possess a high zeta potential value offering stability to the preparation. Such particles resist agglomeration or flocculation and remain dispersed throughout dispersion. When zeta potential value is small, particles experience attractive forces leading to flocculation or aggregation of particles.

\section{Evaluation of Econazole dendrimer hydrogels Percentage drug entrapment studies}

Percentage drug entrapment studies were carried using UV spectroscopic method. These studies determine the efficiency of a preparation method to incorporate drug into the dendrimer gels. To determine the amount of drug encapsulated in gels, known amount of dendrimer gel equivalent to $10 \mathrm{mg}$ was dissolved in $10 \mathrm{ml}$ of methanol and the solution was centrifuged for $10 \mathrm{~min}$ at 100rpm. The resultant filtrate was diluted suitably and observed under UV at $271.5 \mathrm{~nm}$ to determine the drug inside the dendrimer gel complex (Reddy et al., 2014).

\section{Anti-fungal activity of Econazole and drug loaded dendrimer hydrogels}

Anti-fungal activity of synthesized dendrimer hydrogels were investigated using Agar plate Diffusion method. Two human pathogenic fungal strains i.e. Candida krusei and Candida albicans were used for estimating anti-fungal activity of prepared formulations. Petridishes with Sabouraud's agar media were prepared and inoculated $100 \mu \mathrm{L}$ of candidal strains. Later the plates were dried and with the help of a sterile cork borer of diameter $6 \mathrm{~mm}$, wells were made in the agar plates. Simultaneously, known amount of different formulations of dendrimer hydrogels (G2, G3 and G4) equivalent to $10 \mathrm{mg}$ were diluted with $10 \mathrm{ml}$ of methanol and $10 \mu \mathrm{L}$ was transferred to the wells. Hydrogel without econazole and dendrimer (placebo), hydrogel with econazole and hydrogel with ciric acid dendrimer were used as controls and were introduced simultaneously onto agar plates along with G2, G3 and G4 hydrogels.

Plates were then incubated at $37{ }^{\circ} \mathrm{C} \pm 0.1{ }^{\circ} \mathrm{C}$ for $24 \mathrm{~h}$. Antifungal activity was expressed as mean of inhibition zones (mm) around each well (Winnicka et al., 2012). 


\section{Invitro drug release of Econazole from Dendrimer hydrogels}

Diffusion studies of prepared dendrimer hydrogels was carried using Franz diffusion cell and drug release through cellophane membrane was determined by UV spectroscopic method. Gel sample $(0.5 \mathrm{~g})$ was placed on a cellophane membrane in donor compartment with $100 \mathrm{ml}$ of phosphate buffer of $\mathrm{pH} 5.5$ as dissolution medium in receptor compartment ${ }^{18}$. This assembly was maintained on a magnetic stirrer at $37^{\circ} \mathrm{C}$. As the diffusion studies proceed, $1 \mathrm{ml}$ of sample was withdrawn periodically at 0.5 , $1,2,4,6,8,12,24$ and 48hrs from receptor medium and simultaneously replaced with equal amounts of fresh buffer. Collected samples were diluted appropriately and analyzed using UV spectrophotometer at $271.5 \mathrm{~nm}$ with methanol as blank (Rao et al., 2015).

\section{RESULTS AND DISCUSSION}

\section{FT-IR studies}

FT-IR studies were performed both for the drug and drug loaded formulations using FT-IR spectrophotometer. Results of the study showed IR spectrum of pure drug was almost equal to the standard drug, Econazole. In case of drug loaded formulations, characteristic peaks of both drug and dendrimers were at their wavelengths. Results clearly indicated that drug has interacted and there was compatibility between the drug and polymers of dendrimers. Thus there was no change in the chemical integrity of Econazole. (Table no.3, Fig no. 1-4)

\section{Zeta potential}

Zeta potential of drug loaded Dendrimers was determined using Zetasizer. Technique adapted for performing Zeta Potential was Dynamic Light Scattering Technique. The values of Zeta potential for Econazole loaded dendrimers ranged from -37 to -48 , indicating good stability of the formulations (Ciolkowski et al., 2011).

Table 4: Zeta Potential of different Dendrimer Generations.

\begin{tabular}{cc}
\hline Formulation Code & Zeta Potential \\
\hline G2 & -48 \\
G3 & -41 \\
G4 & -37 \\
\hline
\end{tabular}

Stability of the formulations is contributed to the smaller dendritic size and repulsive electrostatic forces of dendrimers (Table no.4).

Table 3: Functional Groups of Infra Red Spectroscopy.

\begin{tabular}{|c|c|c|c|c|c|}
\hline \multirow[b]{2}{*}{ Polymers } & \multicolumn{5}{|c|}{ Groups assigned } \\
\hline & $\begin{array}{c}\text { O-H stretch } \\
\text { cm }^{-1}\end{array}$ & $\begin{array}{c}\text { C-H stretch } \\
\text { cm }^{-1}\end{array}$ & $\begin{array}{c}\mathrm{C}=\mathrm{C} \text { stretch } \\
\mathrm{cm}^{-1}\end{array}$ & $\begin{array}{c}\text { C-C stretch } \\
\text { cm }^{-1}\end{array}$ & $\begin{array}{c}\text { C-O-C stretch } \\
\text { cm }^{-1}\end{array}$ \\
\hline Drug (Econazole) & 3423.20 & 2962.75 & 1640.12 & 1472.58 & 1219.62 \\
\hline Econazole $+\mathrm{G} 2$ dendrimer & 3448.94 & 2966.06 & 1638.30 & 1492.78 & 1231.82 \\
\hline Econazole+G3dendrimer & 3451.48 & 2968.09 & 1638.77 & 1462.05 & 1255.14 \\
\hline Econazole+G4dendrimer & 3441.47 & 2964.84 & 1638.28 & 1465.33 & 1232.46 \\
\hline
\end{tabular}

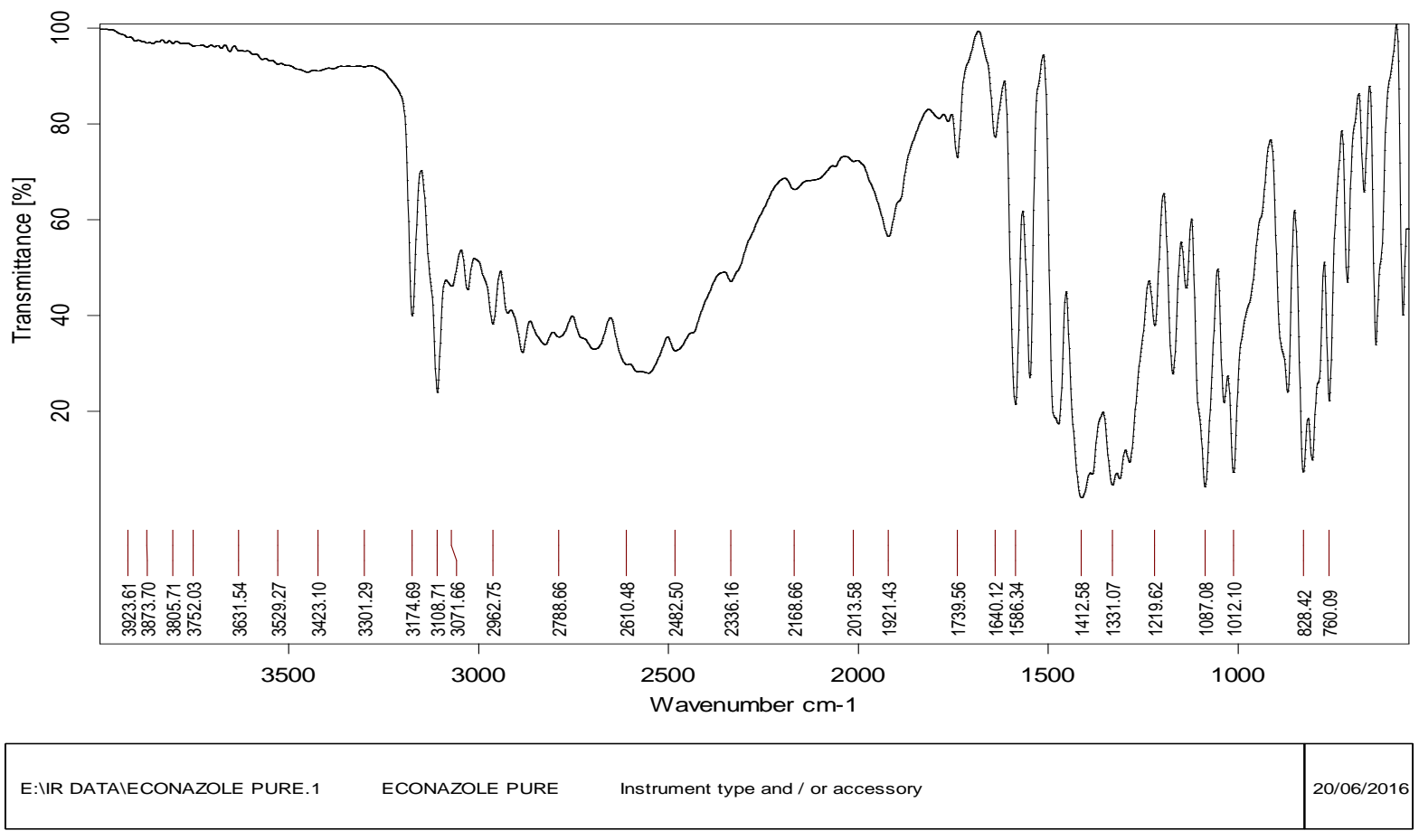

Page 1/1

Fig 1: FT-IR spectrum of Econazole 


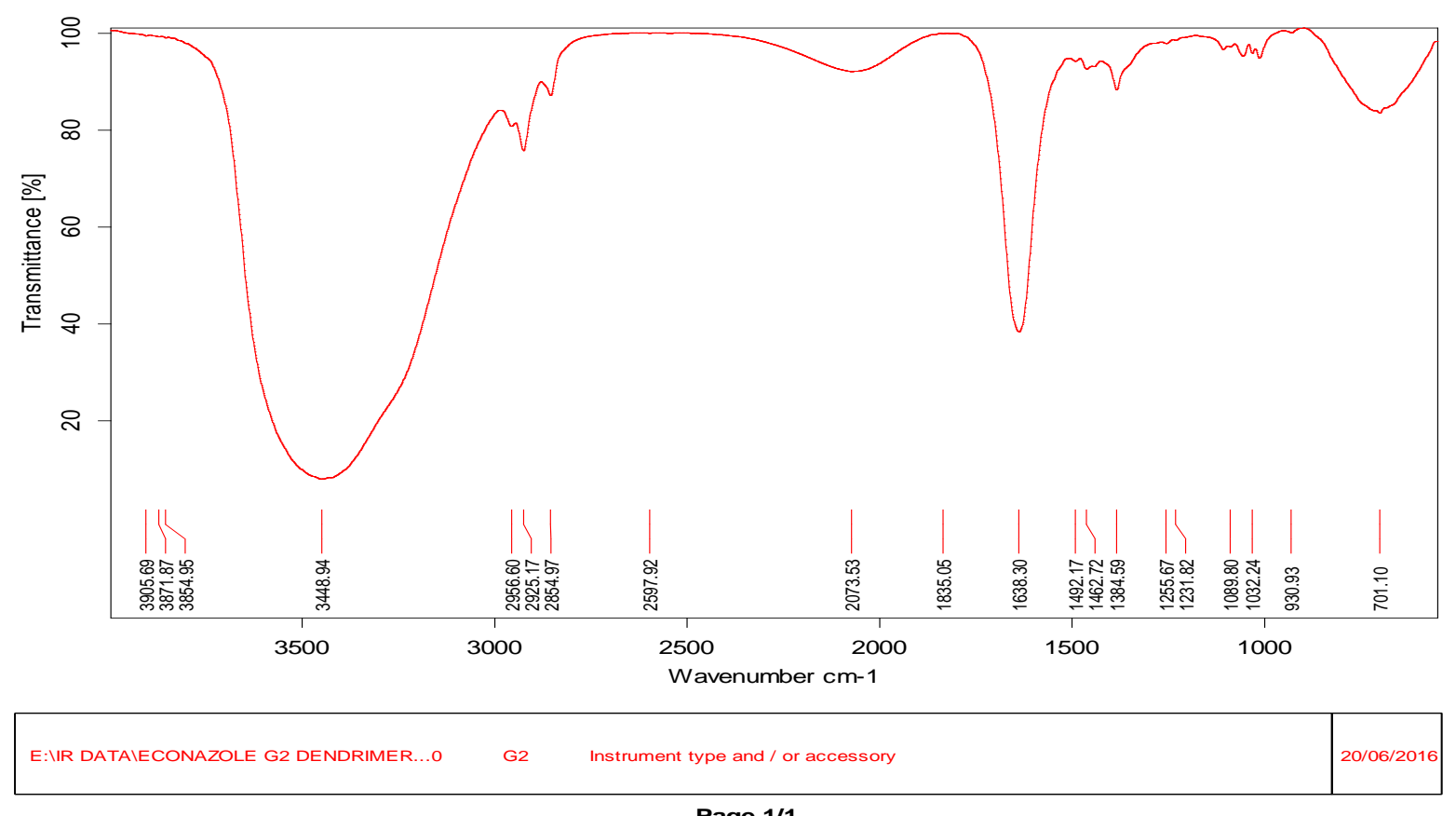

Fig. 2: FT-IR Spectrum of $2^{\text {nd }}$ generation Econazole loaded Dendrimer

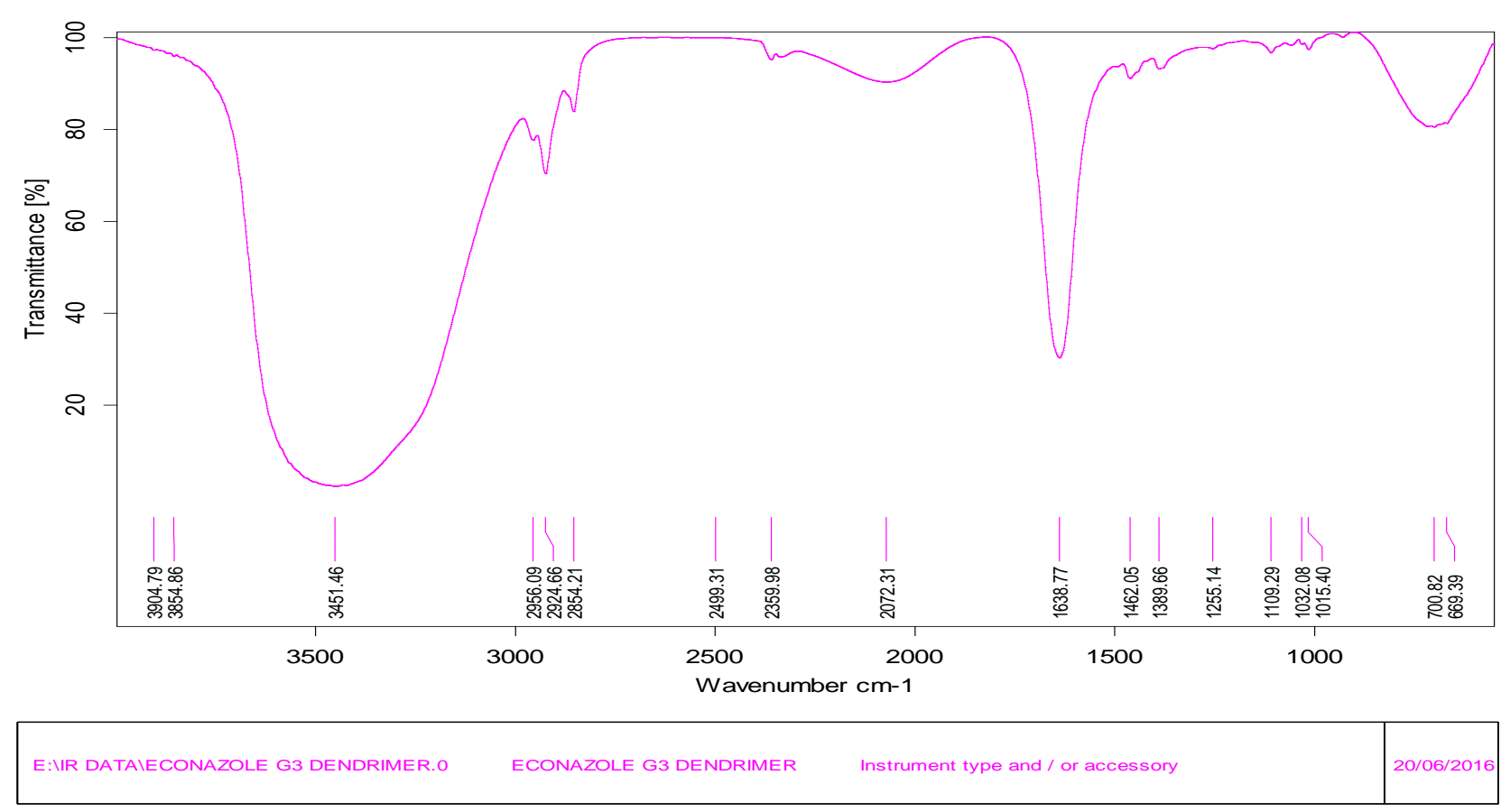

Page 1/1

Fig. 3: FT-IR Spectrum of $3^{\text {rd }}$ generation Econazole loaded Dendrimer 


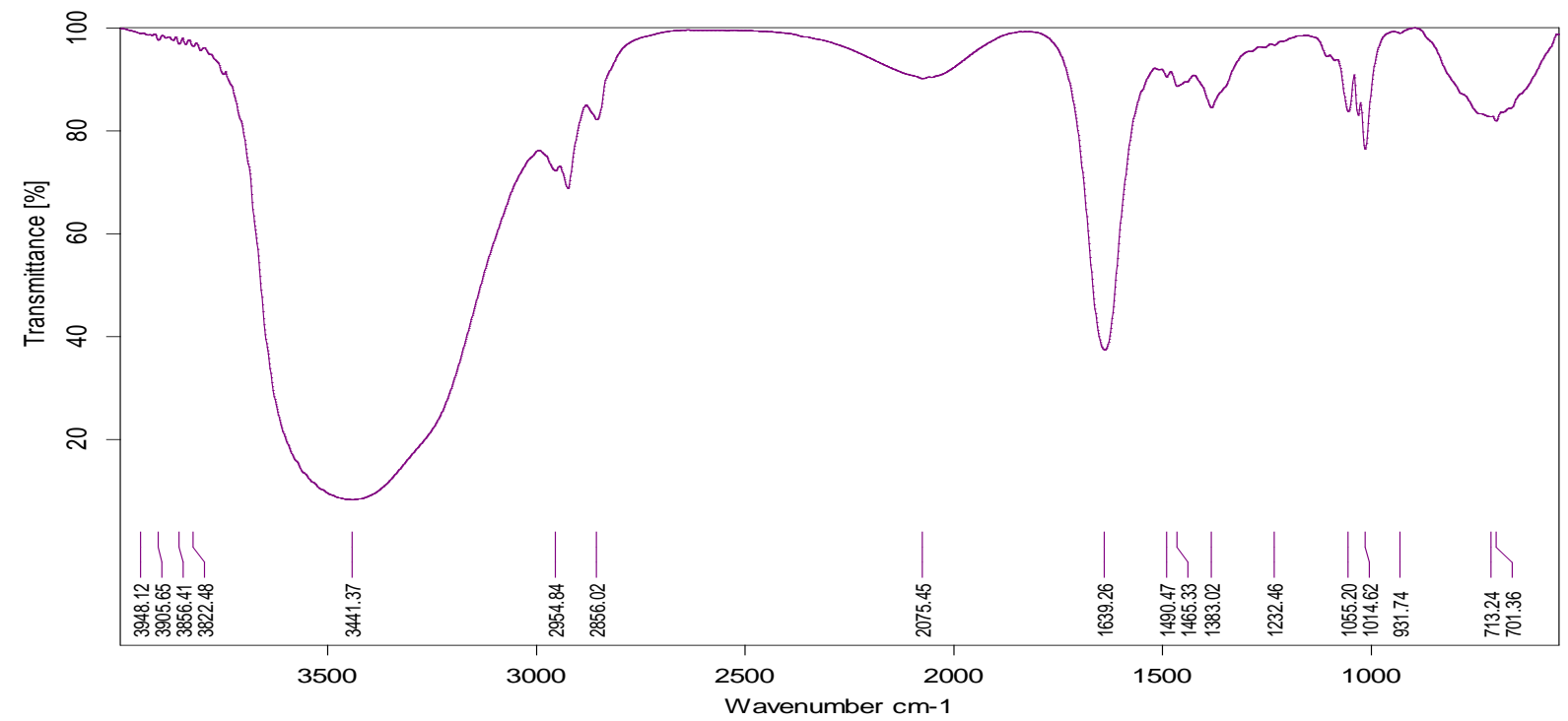

\begin{tabular}{|l|l|l|l|l|l|l|}
\hline E:IIR DATAIECONAZOLE G4 DENDRIMER.0 & G4 $\quad$ Instrument type and / or accessory \\
\hline
\end{tabular}

Fig 4: FT-IR Spectrum of $4^{\text {th }}$ generation Econazole loaded Dendrimer

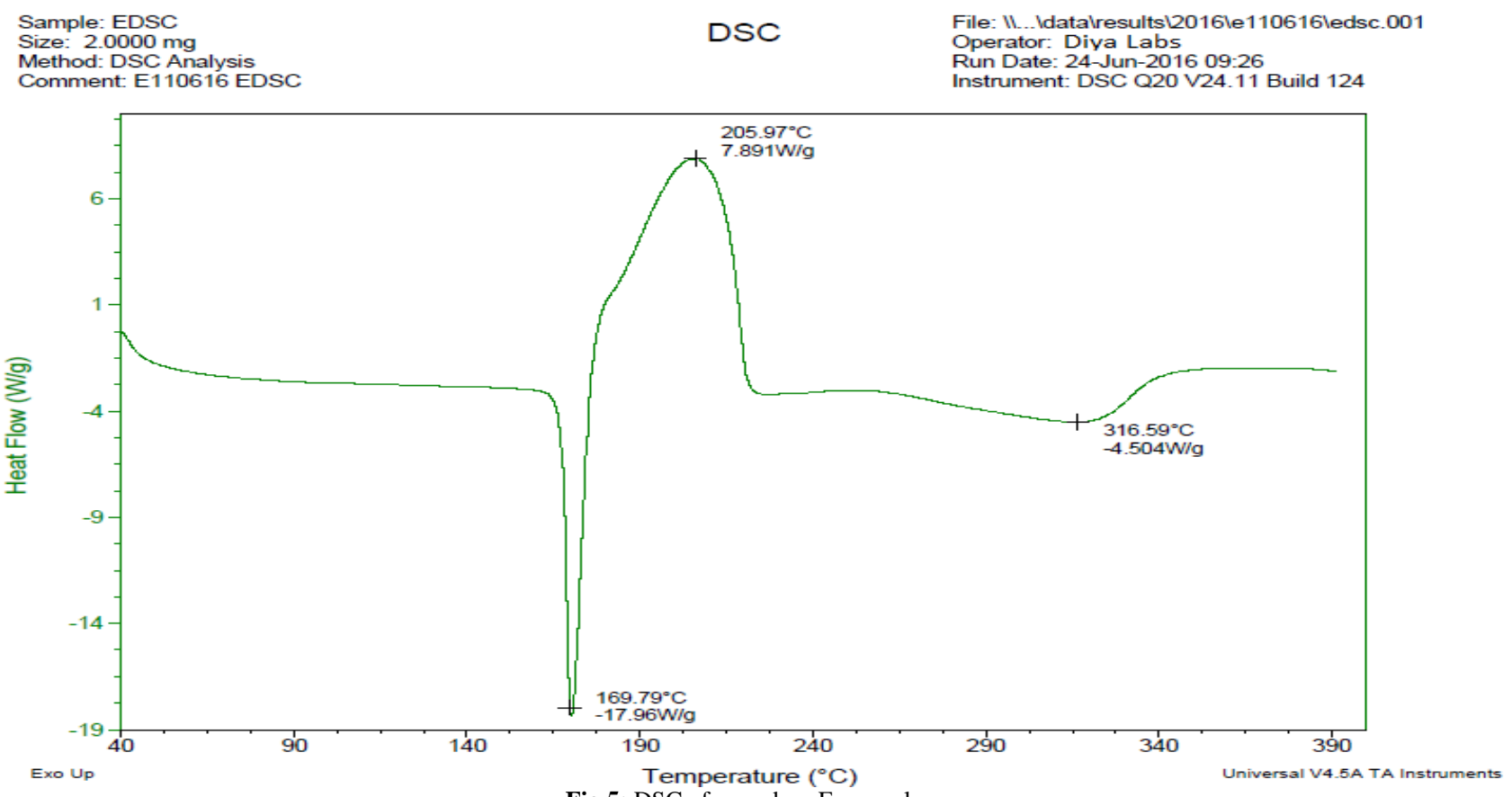

\section{DSC analysis}

Differential scanning calorimetry curves suggested that $4^{\text {th }}$ generation Econazole loaded citric acid dendrimer was not a physical mixture. Upon heating to $90^{\circ} \mathrm{C}$, drug Econazole experienced an endothermic transition which was previously referred as melting point of the compound. Further, broad endothermic peaks were observed between $96.05^{\circ} \mathrm{C}$ and $156.52^{\circ} \mathrm{C}$ for $4^{\text {th }}$ generation Econazole loaded dendrimer. Characteristic peaks of Econazole were almost disappeared in the drug loaded $4^{\text {th }}$ generation dendrimer (Fig no. 5,6). 


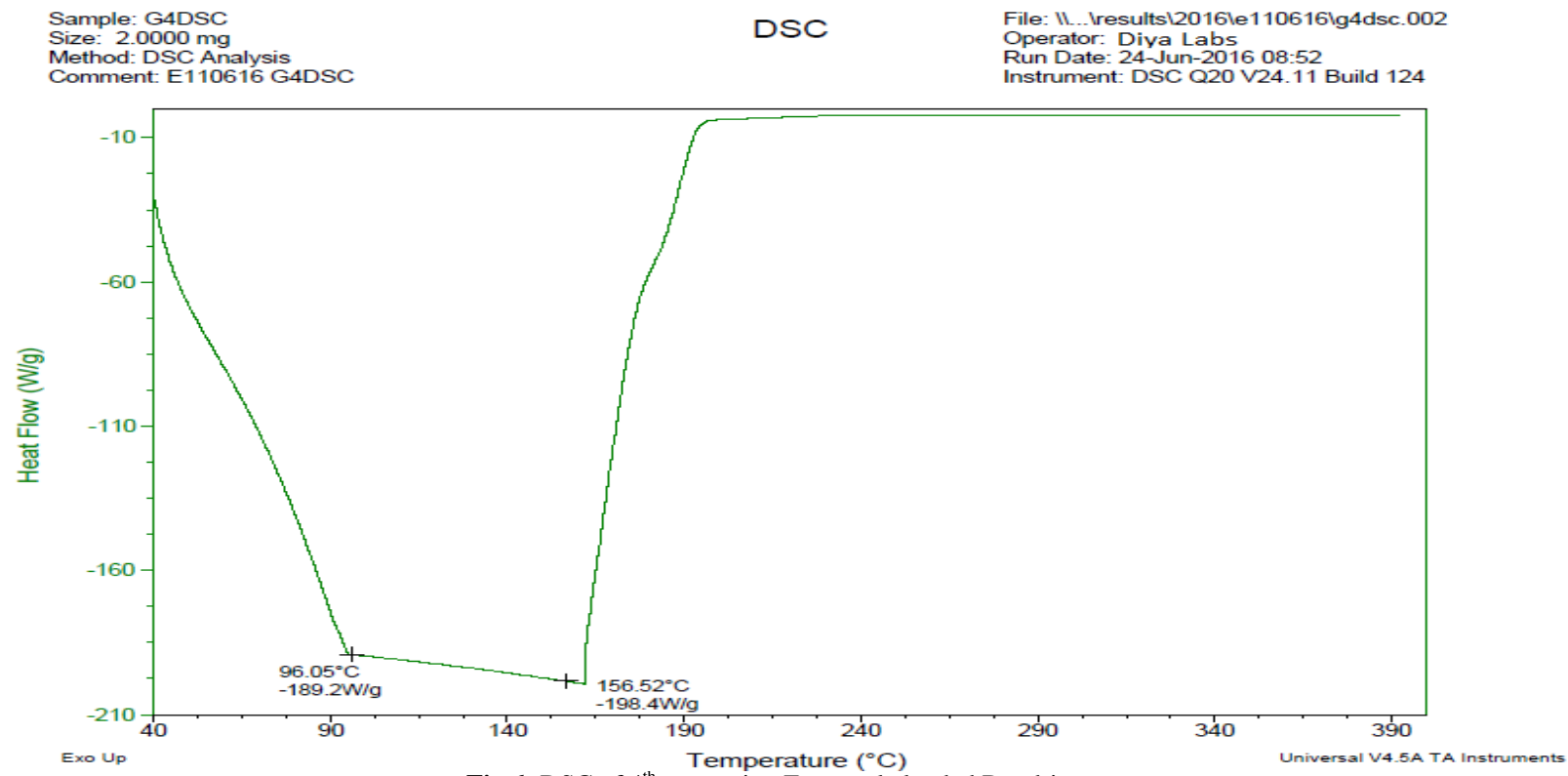

Fig 6: DSC of $4^{\text {th }}$ generation Econazole loaded Dendrimer

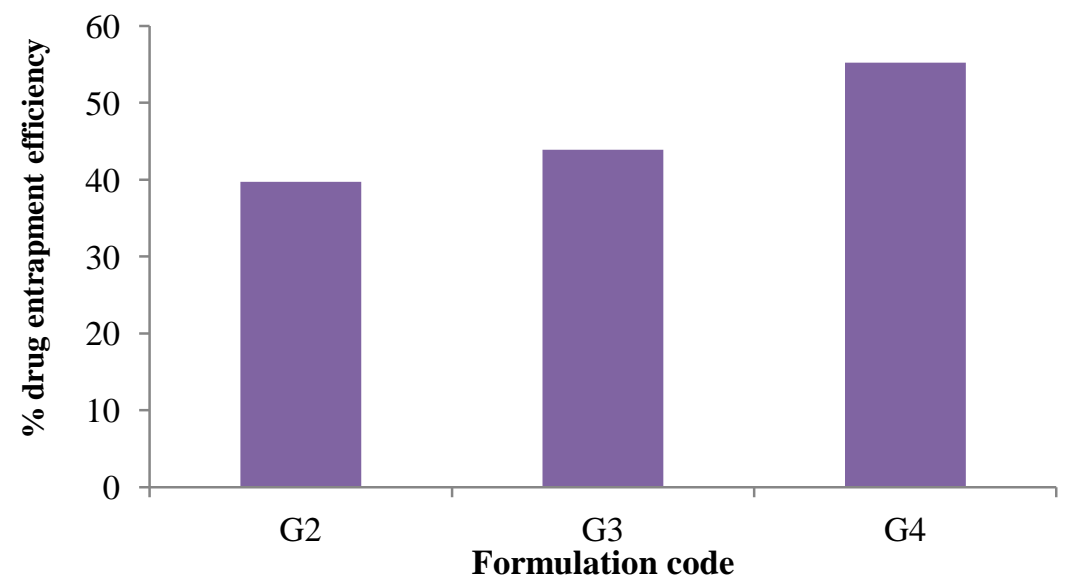

Fig 7: Entrapment efficiencies for Econazole loaded Dendrimer Hydrogels

\section{Percentage drug entrapment studies}

Results of percentage drug entrapment studies for dendrimer hydrogels carried through UV spectroscopic method were in the range 39.7-55.25\%. Drug entrapment was found high for G4 hydrogel i.e., $55.25 \%$ as compared to G2 and G3. Thus from the results it was evident that drug entrapment increases with higher generations (Fig no.7).

\section{Anti-fungal activity of Econazole loaded dendrimer hydrogels}

Influence of dendrimers on the antifungal activity of econazole was clearly seen from the results. Anti-fungal activity of dendrimer hydrogels against Candidal strains increased to a larger extent as compared to the pure drug, Econazole. Among G2, G3 and G4 hydrogels, zone of inhibition was comparatively more for G2 generation. From the results it was believed that, size of the dendrimer molecule affects the penetration ability and anti-fungal activity of encapsulated drugs. Thus, G2 being smaller in size could have penetrated the fungal cells efficiently and cut the growth of fungal strains as compared to G3 and G4 molecules (Table no.5, Fig no. 8).

\section{Invitro drug release studies}

Invitro drug release studies were carried for G2, G3 and G4 Econazole loaded dendrimer hydrogels using phosphate buffer of $\mathrm{pH}$ 5.5. Results of the study clearly demonstrated that dendrimer hydrogels of higher generations i.e., $4^{\text {th }}$ generation was able to sustain the drug release more efficiently as compared to lower generations $\left(2^{\text {nd }}\right.$ and $3^{\text {rd }}$ generations $)$. From the above result, it is clear that as the generations increase complexicity of dendrimers also increase that leads to sustained effect. Release kinetic studies of the formulations showed that they followed Zero order release mechanism. Higuchi matrix equation confirmed that the release followed Diffusion controlled mechanism (Fig no.9). justification has been provided in the e-mail. 

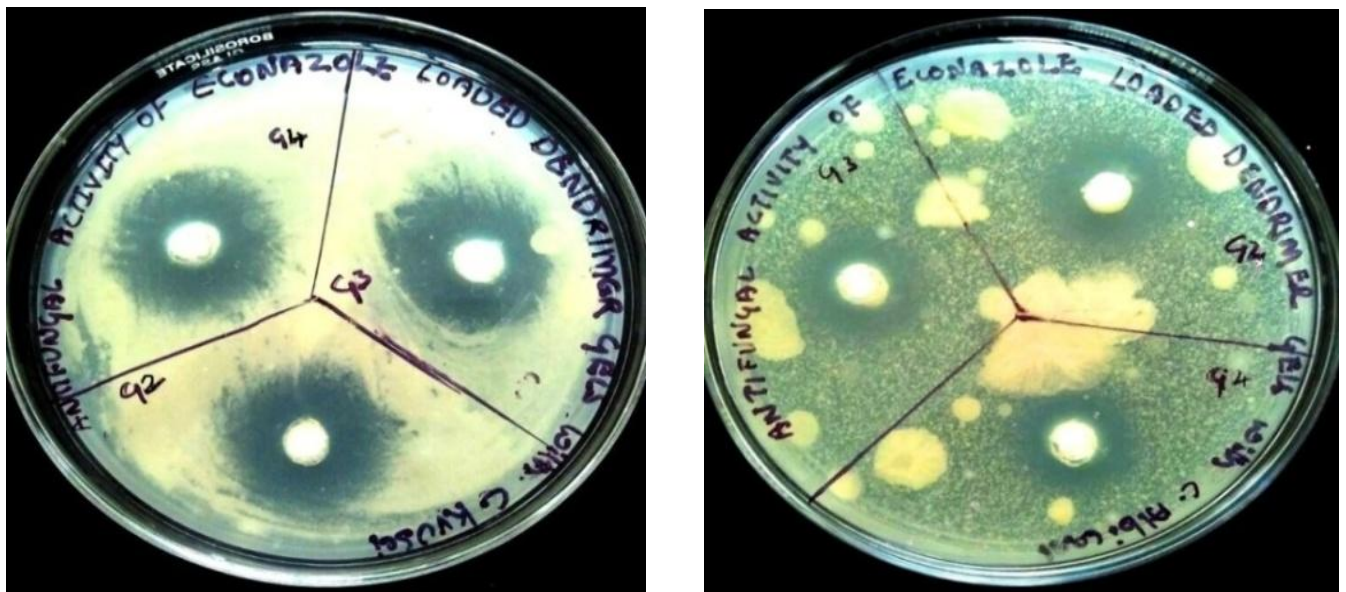

Fig. 8(a): Anti-fungal activity of Econazole on C. krusei Fig. 8(b)Antifungal activity of Econazole on C. albicans.

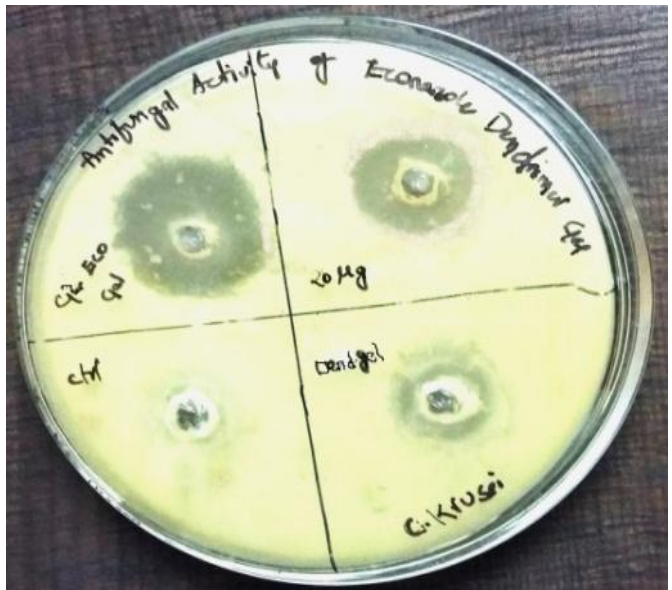

Fig. 8(c) Antifungal activity of placebo, Dendrimer gel, pure drug and drug loaded Dendrimer gel

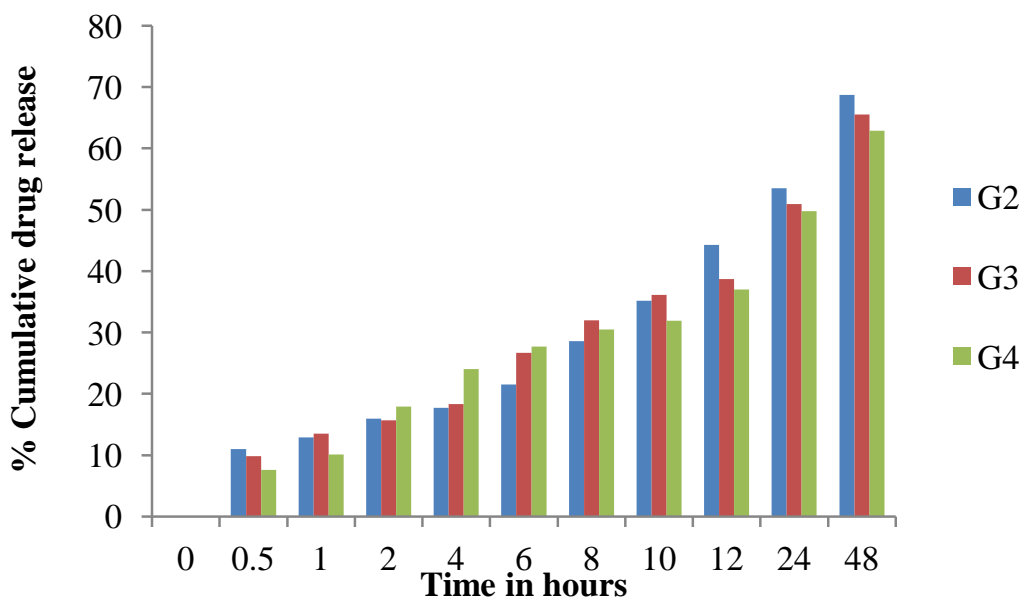

Fig 9: Cumulative drug release of Econazole loaded dendrimer hydrogels.

Table No. 5 Zone of Inhibition for Dendrimer Hydrogels

\begin{tabular}{cccc}
\hline Formulation Code & & Zone of Inhibition (Mm) & C. albicans \\
\cline { 2 - 4 } & C. krusei & 14 \\
G2 & 24 & 12 \\
G4 & 19 & 10 \\
Pure drug & 17 & - \\
Dendrimer gel & 11 & - \\
Placebo & 3 & - \\
\hline
\end{tabular}




\section{CONCLUSION}

In current study, we have designed citric acid dendrimer hydrogels as carriers for the delivery of antifungal drug, Econazole. Synthesized hydrogels were evaluated for various parameters such as entrapment efficiency, DSC analysis, in-vitro drug release, antifungal activity etc. Size and architecture of citric acid dendrimers strongly influences the anti-fungal activity, invitro drug release, entrapment efficiency parameters of drug, econazole. Thus they are considered novel carriers for the delivery of antifungal agent to the resistant producing strains of Candida krusei and Candida albicans for treating topical fungal infections.

\section{Financial support and sponsorship: Nil.}

Conflict of Interests: There are no conflicts of interest.

\section{REFERENCES}

Alberti I, Kalia YN, Naik A, Bonny J, Guy RH. Effect of Ethanol and Isopropyl myristate on the availability of Topical Terbinafine in Human Stratum Corneum, in vivo. Int J Pharm, 2001; 219:11-19.

Albertini B, Passerini N, Sabatino MD, Vitali B, Brigidi P, Rodriguez L. Polymer-Lipid based Mucoadhesive Microspheres prepared by Spray-Congealing for the Vaginal Delivery of Econazole Nitrate. Europ J Pharm Sci, 2009; 36:591-601.

Amaresh P. Dendrimers: The Recent Drug Delivery System, Int Res J Pharm, 2012; 3:10-12.

Cheng Y, Xu Z, Ma M, Xu T. Dendrimers as Drug Carriers: Applications in Different routes of Drug Administration. J Pharm Sci, 2008; 97:123-143.

Ciolkowski M, Rozanek M, Szewczyk M, Klajnert B, Bryszewska M. The influence of PAMAM-OH dendrimers on the activity of Human erythrocytes ATPases. Biochim Biophys Act-Biomem, 2011; 1808:2714-23.

Jain A, Dubey S, Kaushik A, Tyagi AK. Dendrimer: A Complete Drug Carrier. Int J Pharm Sci Res, 2010; 1:38-52.

Janiszewska J, Sowinska M, Rajnisz A, Solecka J, Lacka I and Milewski S. Novel Dendrimeric Lipopeptides with Antifungal Activity. Bioorg Med Chem Lett, 2012; 22:1388-93.

Kakade T, Kadam V, Dhanavade K, Salunkhe V. A Review on Pharmaceutical Nanotechnology: Dendrimers. Wor J Pharm Pharm Sci, $2013 ; 2: 4815-30$.

Maged A, Mahmoud AA, Ghorab MM. Nano Spray Drying technique as a Novel Approach to formulate stable Econazole nitrate Nanosuspension formlations for Ocular use. Mol Pharm, 2016; 13:295165.

Pandey R, Ahmad Z, Sharma S, Khuller GK. Nano Encapsulation of Azole Antifungals: Potential Applications to improve Oral Drug Delivery. Int J Pharm, 2005; 301:268-276.

Rao BN, Viswanath V, Purushothaman M, Vaishnavi VP. Synthesis and Formulation of new Functionalized Citric Acid based Dendrimers for Drug Delivery using an Anti Bacterial agent. World J Pharm Res, 2015; 4:1054-62.
Reddy MS, Tejaswi Y, Kalyan AV, Sravya R, Namrath M. Novel Drug Delivery of Minocycline aganist Bacteria by using a Polymer Citric Acid macro molecule. Ind J Res Pharm Biotech, 2014; 2:1161-66.

Salerno C, Carlucci AM, Bregni C. Study of in vitro Drug Release and Percutaneous absorption of Fluconazole from Topical Dosage Forms. AAPS Pharmscitech, 2010; 11:986-93.

Sosnowska K, Winnicka K. PAMAM Dendrimers affect the in vitro release of Clotrimazole from Hydrogels irrespective of its molecular state. Afr J Pharm Pharmacol, 2013; 7:567-73.

Svenson S. Dendrimers as versatile platform in Drug Delivery Applications. Eur J Pharm Biopharm, 2009; 71:445-462.

Tambe RV, Pakhare SS, Jadhav MG, Tiwari SS, Rai CR. Dendrimer: A Smart Polymer. Int J Res Rev Pharm Appl Sci; 2:513-528.

Tomalia DA. Birth of a New Macromolecular Architecture: Dendrimers as Quantized Building Blocks for Nanoscale Synthetic Organic Chemistry. Aldrich Acta, 2004; 37:39-57.

Venuganti VVK, Perumal OP. Effect of Poly(Amidoamine) (PAMAM) Dendrimer on Skin Permeation of 5-Fluorouracil. Int J Pharm, 2008; 361:230-238.

Venuganti VVK, Perumal OP. Poly(Amidoamine) Dendrimers as Skin Penetration Enhancers: Influence of Charge, Generation and Concentration. J Pharm Sci, 2009; 98:2345-2356.

Vera-Cabrera L, Campos-Rivera MP, Escalante-Fuentes WG, Pucci MJ, Ocampo-Candiani J, Welsh O. In Vitro Activity of ACH-702, A New Isothiazoloquinolone, Against Nocardia Brasiliensis compared with Econazole and the Carbapenems Imipenem and Meropenem alone or in combination with Clavulanic acid. Antimic Agen Chem, 2010; 54:219193.

Vijayakumar P, Choudary RK, Narne R. Efivarenz loaded Novel Citric Dendritic structure for increased Solubility and Sustained Delivery. J Pharm Drug Del Res, 2012; 1:1-5.

Winnicka K, Sosnowska K, Wieczorek P, Sacha PT, Tryniszewska E. Poly(Amidoamine) Dendrimers increase Antifungal Activity of Clotrimazole. Bio Pharm Bull, 2011; 34:1129-33.

Winnicka K, Wroblewska M, Wieczorek P, Sacha PT, Trynniszewska E. Hydrogel of Ketoconazole and PAMAM Dendrimers: Formulation and Antifungal activity. Mol, 2012; 17:4612-24.

Zaman M, Ahmad E, Qadeer A, Rabbani G, Khan RH. Nanoparticles in relation to protein and peptide aggregation. Int $\mathbf{J}$ Nanomed, 2014; 9:899-912.

\section{How to cite this article:}

Rao N, Fathima R, Valikala V, Prakash G, Padmini S, Reddy S. Novel Citric Acid Dendritic Hydrogels for the Delivery of Econazole Nitrate and its Antifungal Activity. J App Pharm Sci, 2016; 6 (12): 094-102. 